\title{
Reflexão sobre a presença do acompanhante na humanização do trabalho de parto
}

\author{
Reflection on the presence of the companion in the humanization of child birth \\ Reflexión sobre la presencia del acompañante en la humanización del parto
}

Recebido: 28/06/2021 | Revisado: 06/07/2021 | Aceito: 09/07/2021 | Publicado: 18/07/2021

Emmanuelle Santos Moura

ORCID: https://orcid.org/0000-0003-0840-5144

Universidade Federal de Sergipe, Brasil

E-mail: emmanuelle-moura@hotmail.com

Ruth Cristini Torres

ORCID: https://orcid.org/0000-0002-8664-192X Instituto de Hematologia e Hemoterapia de Sergipe, Brasil

E-mail: ruthcristini@gmail.com

Weber de Santana Teles

ORCID: https://orcid.org/0000-0003-1770-8278 Centro de Hemoterapia de Sergipe, Brasil

E-mail: arteecura@hotmail.com

Max Cruz da Silva

ORCID: https://orcid.org/0000-0002-6944-5986

Faculdade Pio Décimo, Brasil

E-mail: maxlfi@hotmail.com

Ângela Maria Melo Sá Barros

ORCID: https://orcid.org/0000-0003-4087-3247

Universidade Federal do Rio de Janeiro, Brasil

E-mail: angelsamelo@hotmail.com

Marcel Vinícius Cunha Azevedo

ORCID: https://orcid.org/0000-0002-5312-3333

Centro Universitário Estácio de Sergipe, Brasil

E-mail: marcelvinicius49@gmail.com

Paulo Celso Curvelo Santos Junior

ORCID: https://orcid.org/0000-0001-5834-6782

Universidade Tiradentes, Brasil

E-mail: Paulo.curvelo.jr@gmail.com

Alejandra Debbo

ORCID: https://orcid.org/0000-0002-7743-5921

Universidade Tiradentes, Brasil

E-mail: aledebbo@hotmail.com

Rute Nascimento da Silva

ORCID: https://orcid.org/0000-0002-2719-1623

Universidade Tiradentes, Brasil

E-mail: silva_rute@hotmail.com

André Luiz de Jesus Morais

ORCID: http://orcid.org/0000-0003-4889-8297

Centro Universitário Estácio de Sergipe, Brasil

E-mail: enfermeiro.andre@ hotmail.com

\section{Resumo}

O presente estudo objetivou em analisar o papel do acompanhante diante do processo de humanização do parto e identificar os fatores que dificultam sua presença. Trata-se de uma pesquisa descritiva e exploratória de caráter qualitativo. A amostra foi composta 14 usuárias de uma Unidade Básica de Saúde selecionadas por conveniência que tiveram filhos no município de Aracaju. Para a coleta dos dados foi realizada uma entrevista através de questionário semiestruturado. Evidenciou-se que $87,7 \%$ das entrevistadas gostariam de ter a presença do acompanhante, contudo, a maioria $(58,3 \%)$ não teve o direito assegurado. Intervenções feitas objetivando acalmar a parturiente são medidas que possibilitam calmaria e segurança, tornando o momento do parto mais brando e especial, podem ser citadas entre estas medidas: o dialogo efetivado pelo acompanhante, terapia medicamentosa para aliviar os sintomas, utilização da bola suíça como técnica para minimizar a tensão, diminuir a ansiedade e descomodidade das mulheres que estão em trabalho de parto. Compreende-se que uma Lei que assegure esse direito não é o suficiente para que sua prática seja concretizada, havendo a necessidade da conscientização da população, dos profissionais e gestores.

Palavras-chave: Humanização da assistência; Trabalho de parto; Parto humanizado; Parto. 


\begin{abstract}
This study aimed to analyze the role of the companion in the process of humanization of childbirth and identify the factors that hinder their presence. This is a descriptive and exploratory qualitative research. The sample consisted of 14 users of a Basic Health Unit selected by convenience who had children in the municipality of Aracaju. For data collection an interview was conducted through a semi-structured questionnaire. It was evident that $87.7 \%$ of respondents would like to have the presence of a companion, however, the majority (58.3\%) did not have the right assured. Interventions aimed at calming the parturient are measures that allow calmness and safety, making the time of childbirth more gentle and special. Among these measures are: the dialogue carried out by the companion, drug therapy to relieve symptoms, use of the Swiss ball as a technique to minimize tension, reduce anxiety and discomfort for women who are in labor. It is understood that a law that ensures this right is not enough for its practice to be implemented, with the need for awareness among the population, professionals and managers.
\end{abstract}

Keywords: Humanization of assistance; Labor; Humanized birth; Childbirth.

\title{
Resumen
}

Este estudio tuvo como objetivo analizar el papel del acompañante en el proceso de humanización del parto e identificar los factores que dificultan su presencia. Se trata de una investigación cualitativa descriptiva y exploratoria. La muestra estuvo conformada por 14 usuarios de una Unidad Básica de Salud seleccionados por conveniencia que tenían hijos en el municipio de Aracaju. Para la recolección de datos se realizó una entrevista a través de un cuestionario semiestructurado. Se evidenció que el $87,7 \%$ de los encuestados desearía tener la presencia de un acompañante, sin embargo, la mayoría $(58,3 \%)$ no tenía el derecho asegurado. Las intervenciones dirigidas a calmar a la parturienta son medidas que permiten la tranquilidad y seguridad, haciendo más suave y especial el momento del parto. Entre estas medidas se encuentran: el diálogo que lleva a cabo la acompañante, la farmacoterapia para aliviar los síntomas, el uso de la pelota suiza como técnica para minimizar la tensión, reducir la ansiedad y el malestar de las mujeres que están en trabajo de parto. Se entiende que una ley que garantice este derecho no es suficiente para que se implemente su práctica, con la necesidad de sensibilizar a la población, profesionales y gestores.

Palabras clave: Humanización de la asistencia; Trabajo de parto; Nacimiento humanizado; Parto.

\section{Introdução}

A gravidez e o parto são momentos singulares e quando são vivenciados com dor, angústia, medo e isolamento podem levar a distúrbios psicológicos, afetivos e emocionais. Desta maneira, o acompanhante deve representar o suporte psíquico e emocional, sendo uma presença reconfortante e estímulo positivo nos momentos mais difíceis. (Brasil, Ministério da Saúde 2001).

A nascença de bebê é um momento marcante nas vidas dos cônjuges em especial na da mulher, tendo influência de contextualização social e cultural, essas ocorrências, podem ser entendidas desde o momento do nascimento do ser, sua chegada até o puerpério. Esse processo de mudança maturacional e social, os indivíduos que experimentam necessitam de amparo professional, que operam facilitando com a mudança, objetivando promover o aditamento humano (Giacomini, et al. 2020)

A presença do acompanhante é assegurando pela Lei nº 11. 108, de 07 de abril de 2005, que altera a Lei no 8.080, de 19 de setembro de 1990, para "garantir às parturientes o direito à presença de acompanhante durante o trabalho de parto, parto e pós-parto imediato, no âmbito do Sistema Único de Saúde - SUS”. (Brasil, 2005).

Com a modificação no apoio ao parto na esfera hospitalar, com todo desenvolvimento do parque tecnológico, percebe-se objeção ao acesso as unidades básicas de saúde, aumento das mortes maternas e neonatal, abortos e diminuição na adesão ao aleitamento (Castro \& Clapis 2005).

O entendimento em relação a humanização do parto, pode ter inúmeras conotações, no entanto linhas de pensamento defende como um mecanismo que respeita a unicidade dos indivíduos do sexo feminino, considerando como interprete, acatando a mudança da égide à cultura, conviç̧ões de ponto de vistas dessas pessoas (Largura, 2000).

O termo humanização foi designado pelo Ministério da Saúde, tencionando aperfeiçoar o suporte ao programa de pré-natal, e que os trabalhadores de saúde favoreçam não apenas com a experiência vivenciada em 
relação a gestante, mas que os testemunhos sejam utilizados para que a terapêutica seja efetiva. (Ministério da saúde, 2000).

A presente pesquisa pretende mostrar qual a realidade e a influência da presença do acompanhante durante o trabalho de parto para as parturientes que tiveram ou não este direito assegurado. Para isso, foi formulado um questionário visando à detecção de aspectos positivos e negativos vivenciados por estas mulheres.

Algumas maternidades não apresentam condições mínimas adequadas para permitir a presença de acompanhantes para a gestante do SUS além da resistência das equipes em mudar suas "rotinas". Havendo, assim, um descompasso entre o discurso e a prática. (Brasil, Ministério da Saúde 2001)

Neste cenário emerge o problema da pesquisa: Qual a realidade vivenciada pelas parturientes no decorrer do seu trabalho de parto em relação à presença do acompanhante?

Ao final da pesquisa, espera-se reforçar a discordância entre o que propõe o Ministério da Saúde e a Lei no 11.108 com o que é vivenciado pelas mulheres na hora do seu trabalho de parto. Além de salientar os benefícios da presença do acompanhante como apoio emocional para estas mulheres.

Assim, o presente estudo objetiva analisar o papel do acompanhante diante do processo de humanização do parto e justifica-se à medida que se propõe em avaliar a influência da presença ou ausência do acompanhante na parturização, levando em conta que embora seja direito legal, sua implementação merece ser discutida para que se concretize.

\section{Material e Métodos}

Trata-se de uma pesquisa qualitativa com caráter descritivo e exploratório. A amostra foi do tipo não probabilística por conveniência, que de acordo com Schillewaert, Langerak e Duhamel (1998), é aquela em que a seleção dos elementos da população para compor a amostra depende parcialmente do julgamento do pesquisador no campo e são selecionados os membros da população mais acessíveis.

Foram inclusas as mulheres com idade maior ou igual a 18 anos que tiveram filhos em maternidades públicas e privadas na cidade de Aracaju que são atendidas por uma Unidade Básica de Saúde e aceitaram participar da pesquisa.

A delimitação do grupo, mulheres que tiveram filhos no ano de 2014, com idade maior ou igual a 18 anos que tiveram filhos em maternidades públicas e privadas na cidade de Aracaju que são atendidas em uma Unidade Básica de Saúde e aceitaram participar da pesquisa, este perfil foi escolhido, pois pretende-se colher histórias e experiências variadas, o que não seria possível se fosse apenas em uma maternidade, onde encontra-se normas já estabelecidas.

A coleta de dados foi realizada no período de janeiro a dezembro de 2014 por meio de um questionário semiestruturado elaborado exclusivamente para esta pesquisa, com a finalidade de conhecer as experiências das mulheres da amostra sobre a presença ou não de um acompanhante na sala de parto, bem como questões inerentes ao parto humanizado.

Antes de ser iniciada a pesquisa o questionário foi submetido a um pré-teste com 10 (dez) mulheres visando identificar possíveis falhas no instrumento ou necessidade de adequação do mesmo. Porém, não foi detectada nenhuma dificuldade para sua aplicação e próprio foi utilizado.

A pesquisa respeitou as normas estabelecidas na Resolução do Conselho Nacional de Saúde nº 466/12 que regulamenta a pesquisa com seres humanos, e só foi iniciada após aprovação do Comitê de Ética e Pesquisa. Às participantes foi explicada a pesquisa e seus objetivos e solicitada a leitura, entendimento e assinatura do "Termo de Consentimento livre e esclarecido (TCLE) (Brasil, 2012). A pesquisa foi submetida à avaliação do Comitê de Ética em Pesquisa por meio da plataforma Brasil, sendo aprovada sob o número 1056721.

Os discursos foram submetidos à técnica de análise de conteúdo, na qual Bardin (2009) define como um conjunto de técnicas de análise das comunicações. O objetivo desta técnica é a busca dos sentidos contidos sob documentos, material coletado 
através de entrevistas (Campos 2004). As falas das entrevistadas foram separadas em grupos temáticos (variáveis) em consequência da semelhança de significados permitindo a análise qualitativa. Em alguns casos houve a necessidade de citar literalmente alguma descrição, as entrevistadas foram identificadas seguindo a ordem numérica de participação no estudo.

\section{Resultados}

A amostra foi constituída por 14 mulheres com média de idade de 24 anos e desvio padrão de 6,114. Ao considerar a cor autodeclarada, verificou-se que $9(64,3 \%)$ se declararam da cor parda, $4(28,6 \%)$ negra, $1(7,1 \%)$ amarela e nenhuma se declarou da cor branca. Este fato reflete o grande processo de miscigenação presente em nossa região.

Ao analisar o grau de escolaridade, predominaram-se as 7 (50\%) mulheres que alegaram possuir ensino médio completo, seguidas por $6(42,9 \%)$ com ensino médio incompleto e somente $1(7,1 \%)$ afirmou possuir ensino superior completo. Em relação ao estado civil, verificou-se que 6 (24\%) mulheres são solteiras, destas 3 (50\%)apenas planejaram a gravidez. Dentre as mulheres casadas ou que possuíam união estável, 3 (37,5\%) alegaram que não planejaram a gravidez e 5 (62,5\%) planejaram (Figura 1).

Figura 1. Distribuição de mulheres de acordo com o estado civil e o planejamento da gravidez. Aracaju, Sergipe, 2019.

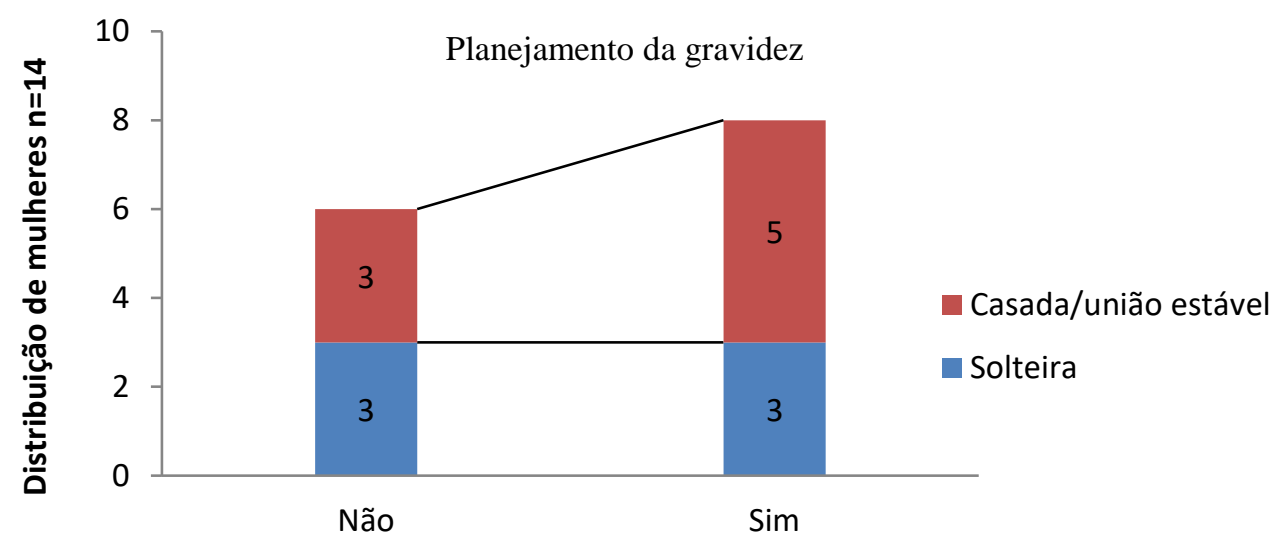

Fonte: Elaboração própria.

Ao associar o número de gestações, partos e abortos (GPA) com o planejamento da gravidez, constatou-se que das mulheres que possuíam apenas um filho, 28,7\% não planejaram a gravidez e $5(35,6 \%)$ planejaram. Entretanto, a mulher que possuía mais filhos (cinco) afirmou não ter planejado pelo menos a última gravidez.

Toda a população amostral afirmou ter realizado acompanhamento pré-natal. Notou-se que 2 (14,3\%) mulheres realizaram 5 consultas, número inferior ao recomendado pelo Ministério da Saúde (2006), 9 (64,2\%) mulheres realizaram de 6 a 9 consultas e $3(21,3 \%)$ realizaram entre 10 e 15 consultas.

A pesquisa demonstra que $5(35,7 \%)$ mulheres tiveram atendimento em maternidade pública, sendo que $3(60 \%)$ partos dessas mulheres foram cesáreos; 3 (21,4\%) mulheres foram para maternidade privada, e a maioria representada por $66,6 \%$ tiveram parto cesáreo; as demais $6(42,8 \%)$ mulheres foram para maternidade filantrópica e estas contrapondo com os outros resultados foram submetidas ao tipo de parto natural (Quadro 1). 
Quadro1. Local de nascimento do último filho e tipo de parto. Aracaju, Sergipe, 2019.

\begin{tabular}{|c|c|c|c|c|}
\hline & & \multicolumn{2}{|c|}{ Tipo de parto } & \multirow[t]{2}{*}{ Total } \\
\hline & & Cesáreo & Natural & \\
\hline \multirow{3}{*}{$\begin{array}{l}\text { Local de nascimento do } \\
\text { último filho? }\end{array}$} & Maternidade pública & 3 & 2 & 5 \\
\hline & Maternidade privada & 2 & 1 & 3 \\
\hline & Maternidade filantrópica & 2 & 4 & 6 \\
\hline \multicolumn{2}{|l|}{ Total } & 7 & 7 & 14 \\
\hline
\end{tabular}

Fonte: Elaboração própria.

Ao considerar a escolha do tipo de parto, 12 parturientes $(85,7 \%)$ avaliadas relataram que não escolheram o parto, destas $7(58,3 \%)$ foram submetidas ao parto cesáreo e $5(41,6 \%)$ ao parto natural. Entretanto, somente $2(14,2 \%)$ gestantes teve a escolha sobre o parto e preferiram o natural.

Notou-se que $85,7 \%$ das entrevistadas tiveram interesse em ter um acompanhante. Todavia, só foi permitida a entrada de $35,7 \%$ do total apresentado (Figura 2).

Figura 2. Distribuição de mulheres de acordo com o interesse em ter acompanhante relacionado. Aracaju, Sergipe, 2019.

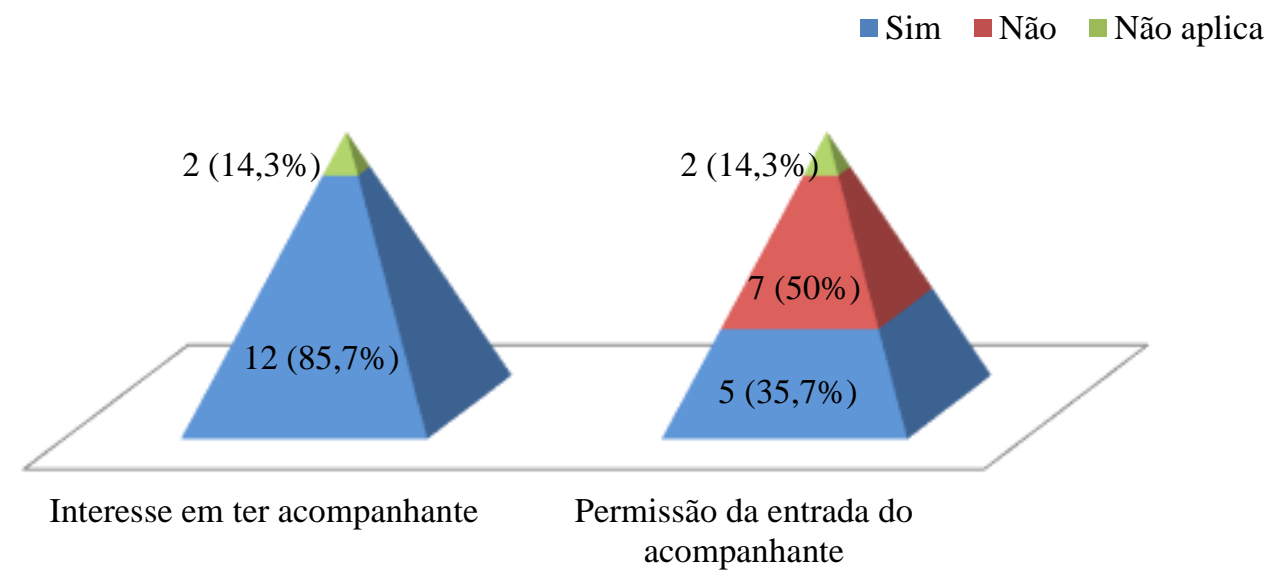

Fonte: Elaboração própria.

Quanto a possibilidade da entrada do acompanhante, as maternidades privadas permitam $100 \%$ da entrada do acompanhante, já a maternidade pública a porcentagem foi de $40 \%$. Na maternidade filantrópica não foi permitida a entrada de nenhum acompanhante. (Figura 3). 
Figura 3. Distribuição da presença do acompanhante dos três tipos de maternidade. Aracaju, Sergipe, 2019.

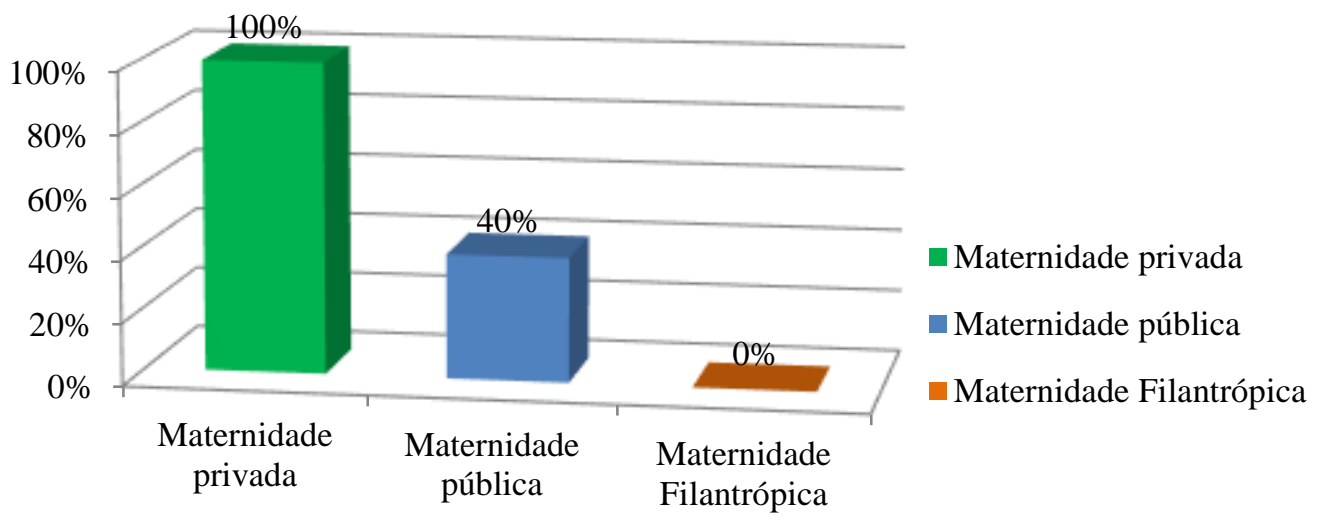

Fonte: Elaboração própria.

Alguns discursos sobre o que mudaria se fosse permitida a entrada do acompanhante merecem ser considerados:

Se minha mãe estivesse comigo me sentiria mais segura. (S10)

Ficaria mais confiante (S12)

Me sentiria mais calma e confiante para ter minha filha (S8)

Me sentiria mais segura se o pai do meu filho estivesse comigo. Lá na sala que eu fiquei tinha muita mulher gritando, fiquei traumatizada. (S5)

Queria que o meu marido participasse desse momento. Acho que seria importante como pai. (S14)

Se eu pudesse escolheria a minha mãe pois ela é meu porto seguro. (S11)

Não sei (S13)

As entrevistadas que tiveram interesse em acompanhante foram questionadas sobre qual motivo não foi permitida a entrada do acompanhante (tabela), onde as descrições mais frequentes foram:

A equipe do hospital disse que só poderia ter acompanhante do sexo feminino. (S5)

Me disseram que não poderia, mas não o porque. (S10)

Me disseram que o hospital não tinha espaço e nem roupa apropriada para o acompanhante. (S8)

Me disseram que ter acompanhante era coisa de maternidade particular e mesmo assim só pagando. (S12)

Não sabia que podia. (S11)

O pessoal de lá não falou nada. Minha irmã também teve filho lá e não pode. (S14)

Dentre as respostas acerca do que representou a ausência do acompanhante no momento tão importante as mulheres responderam que:

Eu estava muito fraca, fiquei nervosa. Além dos médicos serem ignorantes. (S11)

Fiquei muito nervosa. Foi tudo diferente do que eu queria. (S8)

Foi ruim. Me senti muito só sem poder contar com alguém de confiança. Meu psicológico ficou abalado por que já perdi uma irmã enquanto ela paria e achei que isso poderia acontecer comigo. (S5)

Me senti insegura e com medo. Só pensava em ir para casa. (S12)

Me senti sozinha e com um pouco de medo. (S12)

Nunca pensei sobre isso, acho que não representou nada. (S13) 
Para as que tiveram a presença do acompanhante foi questionado sobre o que eles representaram naquele momento e as entrevistadas descreveram:

Alivio e Segurança (S3) e (S4)

Ela me passou confiança. Eu tinha medo que alguém levasse a minha filha. (S9)

Tudo. Um anjo da guarda (S1)

Não sabia que podia (S13)

As descrições sobre quem foi escolhido para ser o acompanhante e o porquê da escolha estão transcritas a seguir:

Mãe / Representa confiança pra mim. O pai não é presente e não liga para a criança. (S4)

Marido / Por segurança e compartilhar o momento emocional. (S3)

Outro / Por que minha irmã é a pessoa mais próxima de mim. (S7)

Outro / Minha irmã se ofereceu e eu gostei que ela foi. (S9)

Outro / A única pessoa disponível. (S1)

Em relação a caso não tivesse a presença do acompanhante no momento do parto teria alguma diferença, as mulheres relataram que:

Sim. Ficaria nervosa. (S1)

Eu iria chorar de insegurança e medo de algo dar errado com meu filho. (S3)

Ficaria com vergonha de pedir ajuda e tirar dúvidas com a equipe de enfermagem. Com minha mãe me senti segura. (S4)

Não. (S7)

Sim. Minha pressão ia aumentar, teria medo de morreu sozinha, seria horrível. (S9)

\section{Discussão}

Evidencia-se que a impossibilidade de ter uma pessoa de confiança na hora do seu parto gera sentimentos negativos para esta mulher em um momento tão especial para a sua vida. Com base nos depoimentos e comparações entre as falas das entrevistadas que tiveram ou não o direito assegurado é notório a diferença e a importância do acompanhante para um parto humanizado.

Destaca-se o fato que a maioria dessas mulheres afirmou ter planejado a gravidez, independente do estado civil e idade, notou-se também uma incerteza na hora da resposta para tal questionamento, o que pode sugerir um desconhecimento sobre o significado do planejamento familiar confundindo-o com a aceitação da gravidez. Segundo um estudo realizado com mulheres em idade reprodutiva sobre o planejamento familiar mostrou-se que o significado deste está atrelado ao contexto social, econômico e cultural ao qual a mulher está inserida. E que a assistência ao planejamento familiar não é satisfatória, pois é realizada de forma isolada e não há uma priorização como os demais componentes da atenção básica (Silva, et.al 2011).

Quanto ao acesso ao pré-natal, evidenciou-se que a adesão da área de abrangência da UBS analisada está sendo eficiente à medida que proporciona as gestantes um número satisfatório de consultas. Isto reflete na qualidade da assistência prestada pela equipe de saúde. O profissional enfermeiro, realiza consultas de pré-natal de gestantes de baixo risco, atuando no acompanhamento destas através do cadastro da gestante no SIS Pré natal, na abertura do Cartão da Gestante, realizando anamnese e exame físico geral e obstétrico, solicitando exames já preconizados pelo Ministério da Saúde e na realização de testes rápidos. Estas medidas, em conjunto, visam à detecção precoce de riscos que podem interferir na saúde da futura mãe e do seu filho (Brasil, Ministério da Saúde 2012).

O pré-natal possui grande valia, pois permite a orientação às gestantes acerca das modificações fisiológicas do seu corpo, na identificação de alterações de alerta, os cuidados pertinentes a cada etapa gestacional, na atualização do calendário de vacinação e, além disso, a mantém informada sobre o local onde será realizado o parto e os seus direitos em relação a este. 
Dentre esses direitos está o conhecimento sobre o direito ao acompanhante no trabalho de parto, parto e pós-parto imediato (Brasil, Ministério da Saúde 2012).

No município de Aracaju encontra-se 4 maternidades. Uma maternidade pública destinada ao atendimento de gestantes de alto risco com cobertura de todo o Estado sergipano; uma maternidade filantrópica, também regional que atende o estado de Sergipe e cidades circunvizinhas (Bahia e Alagoas); e por fim, duas maternidades privadas para convênios e atendimento particulares.

Houve um predomínio de parto normal na maternidade filantrópica, o que já era esperado, uma vez que presta assistência a gestantes que não apresentam risco a sua gestação e há um incentivo por parte do Ministério da Saúde e pela Organização Mundial de Saúde por este tipo de parto. O número maior de partos cesáreos na maternidade pública deve-se ao fato de admitir mulheres com gestação de alto risco. Esta requer uma rápida ação para a preservação da vida do binômio mãe-filho justificando assim, a escolha por este parto. Enquanto isso, na maternidade privada o maior número de cesáreas pode ser atribuído ao agendamento prévio por parte dos médicos para a sua comodidade.

O índice de parto cesáreo em maternidade privadas é um tema importante a ser discutido por conta do seu crescente aumento. Uma pesquisa realizada para analisar os aspectos relacionados à escolha do tipo de parto comparando uma maternidade pública com uma particular na cidade de São Luís, capital do estado do Maranhão, identificou um índice de cesarianas maior em maternidades particulares, sendo que na maternidade pública tiveram uma indicação clínica registrada, sendo a desproporção céfalo-pélvica, a doença hipertensiva específica da gravidez e o sofrimento fetal as principais. Já na maternidade privada apenas 60\% dos casos havia uma documentação de indicação clínica (Mandarino 2014).

Outro dado que chama a atenção é que a grande maioria das mulheres $(85,71 \%)$ não escolheu o tipo de parto, sendo que muitas delas não souberam relatar o motivo da escolha. Esta situação tira o papel da mulher de ser protagonista do seu próprio parto e priva o direito da mesma de escolher junto com o médico para uma decisão consciente e segura.

Quanto ao tema central do estudo, a presença do acompanhante no parto, foi questionado às participantes se tinham conhecimento sobre a Lei que assegura este direito. A maioria, 64,3\% relataram que sabiam e que a enfermeira durante a consulta do pré-natal as haviam informado. Porém, 35,7\% ainda não tinham conhecimento e se surpreenderam quando receberam a informação. Apesar de a prevalência ser de mulheres que sabiam do direito, isto ainda não é o suficiente. Todas as mulheres deveriam ter acesso a esta informação antes do parto para poder usufruir o seu direito. Levando em conta que as participantes realizaram o pré-natal na UBS não há justificativa plausível para a desinformação.

Como levantado na hipótese do estudo, a maior parte a amostra (87,7\%) gostariam de poder ter a presença do acompanhante durante o trabalho de parto, contudo, a maioria (58,3\%) não teve o direito assegurado. Para estas, vários fatores foram relatados, entre deles, destacam-se: a impossibilidade da presença de homens na sala de parto, a falta de espaço e de vestuário para o acompanhante e que só em maternidades particulares é que poderiam ter acompanhantes.

A gestante fica a mercê da instituição quando vai ter seu filho e deseja ter uma pessoa para acompanhar o seu parto, mesmo com uma lei que lhe garanta esse direito. A mulher e seu possível acompanhante ficam submissos à decisão da equipe de profissionais que estabelece uma relação de poder, onde os mesmos podem excluir o acompanhante sem uma justificativa aceitável, reforçando a medicalização do parto (Longo, et al. 2010).

Os sentimentos que geraram pela ausência do acompanhante são semelhantes em grande parte das mulheres. Elas relataram que se sentiram inseguras, com medo, nervosas e sozinhas. Estas emoções surgem, pois no momento do parto, as parturientes ficam mais sensíveis por vários motivos: a dor é intensa, existe a preocupação de algo dar errado e, por vezes, falta um acolhimento adequado com a equipe de profissionais. 
Além disso o suporte emotivo ficou claro nesse estudo, em que as gestantes testemunharam que a companhia de alguém minimiza o sentimento de solidão, sensação e dor, devido ser um instante em que o medo invade sua mente e seu coração, e ter um acompanhante ao seu lado diminuiria a tensão. (Dodou, et al. 2014).

Tranquilizar a gestante que se encontra em trabalho de parto, segurando a mão, refrescar sua face, dar um pouco de água, massagear costas e mudar de posição auxilia no estado emocional vivenciado. Esse conforto aliado as técnicas de relaxamento e respiração é extremamente importante para a mulher que está em trabalho de parto. (Souza \& Gualda 2016).

Outro fator importante para a parturiente é o dialogo efetivado pelo acompanhante, que gera segurança e calmaria ofertando clima favorável que confere distração e acima de tudo confiança. (Brüggemann et al. 2007).

A terapia medicamentosa é utilizada para aliviar os sintomas das parturientes e a execução concordante da hora dourada. Há inúmeras metodologia não invasivas para a o aliviamento da aflição, que carecem de ser utilizadas pelas maternidades, adiando as interversões invasivas (Severo et al. 2021).

Vale a pena ressaltar que a utilização da bola suíça está sendo utilizada como técnica para minimizar a tensão, diminuição da ansiedade, descomodidade das mulheres que estão em trabalho de parto, objetivando o lenitivo da dor devido ao nascimento do neonato (Gois et al. 2020).

Segundo Carneiro et al (2020) verifica-se que a metodologia supracitada, não está efetivamente esclarecido no ramo da medicina que se ocupa da gravidez, do parto e da evolução da saúde feminina no período imediatamente subsequente a ele, devido a escassez nas plataformas cientificas.

Ao serem questionadas sobre o que seria diferente se houvesse a presença de uma pessoa de sua escolha na hora do parto, as mesmas relataram que se sentiriam mais calmas, confiantes e seguras para terem seus filhos, sendo que uma das entrevistadas destacou que queria a presença do marido na hora do parto, pois seria importante para o mesmo exercer o seu papel de pai.

Para aquelas que tiveram interesse em ter acompanhante e a entrada foi permitida, foi indagado qual a pessoa e o motivo para tal escolha. Mãe, marido e irmã foram as pessoas que as mulheres escolheram para estarem ao seu lado no momento importante, hora do nascimento do seu filho. As razões para a escolha destas pessoas foi o que elas representavam para cada mulher e pela disponibilidade das mesmas. As participantes da pesquisa mencionaram o que sentiu com a presença de cada acompanhante, sendo o sentimento de alivio, segurança, confiança o que mais se destacaram.

\section{Considerações Finais}

Observou-se uma medicalização do parto, onde a mulher perde o seu direito de atuação como protagonista do nascimento do seu filho e exerce papel de coadjuvante deste momento.

Para que o direito ao acompanhante seja assegurado é importante que as gestantes tenham conhecimento para que assim possa desfrutar do mesmo. O pré-natal é uma importante ferramenta para que essa orientação seja realizada. Porém, as maternidades também têm de ter se adequar para acolher este acompanhante e possibilitar que ele seja um colaborador para um parto tranquilo e humanizado, direito de todas as mulheres.

É de suma importância e valia ter uma lei que assegure esse direito para as mulheres, mas isso não é o bastante. Tem de haver uma conscientização entre os profissionais e gestores para que na prática possa acontecer de forma mais abrangente. Entende-se, também, que a realização de mais pesquisas sobre o tema é bom mecanismo para conhecer a realidade vivenciada pelas parturientes e, assim, contribuir para que de fato a lei seja cumprida.

Conclui-se que esta pesquisa sirva de modelo para uma reflexão a profissionais e coordenadores que atuam diretamente no atendimento da gestante, propiciando qualidade nos atendimentos e serviços prestados à puérpera e recém-nascido, provendo ações que venham a fortalecer à pratica da amamentação. 


\section{Referências}

Bardin, L. (2009) Análise de conteúdo. Edições 70.

Brasil, Ministério da Saúde (2000). Portaria MS/GM nº 569, 01 de junho de 2000

Brasil. (2005). Lei n. 11.108, de 7 de abril de 2005. Altera a Lei n. 8.080, de 19 de setembro de 1990, para garantir às parturientes o direito à presença de acompanhante durante o trabalho de parto, parto e pós-parto imediato, no âmbito do Sistema Único de Saúde - SUS.

Brasil. Ministério da Saúde (2001). Secretaria de Políticos de Saúde. Área Técnica de Saúde da Mulher. Parto, aborto e puerpério: assistência humanizada à mulher-Brasília: Ministério da Saúde. 199.

Brasil. Ministério da Saúde (2012). Secretária de Atenção à Saúde. Departamento de Atenção Básica. Atenção de Pré-Natal de Baixo Risco. Brasília: Editora do Ministério da Saúde.

Brasil. (2012). Resolução $n^{\circ}$ 466, de 12 de dezembro de 2012. Aprovar as diretrizes e normas regulamentadoras de pesquisas envolvendo seres humanos.

Brüggemann, O. M. et al. (2007). A. Apoio no nascimento: percepções de profissionais e acompanhantes escolhidos pela mulher. Rev Saúde Pública. 41(1), 4452 .

Campos, C. J. G. (2004) O método de análise de conteúdo: ferramenta para a análise de dados qualitativos no campo da saúde. Rev. Bras. Enfermagem. 57(5), $611-4$.

Carneiro, E. C. S. P. et al. (2020). O olhar do estudante médico em relação ao parto humanizado em maternidade mageense: aprendizado e Merleau-Ponty. Research, Society and Development, 9(5), e116953230.

Castro, J. C. \& Clapis, M. J. (2005). Parto Humanizado Na Percepção Das Enfermeiras Obstétricas Envolvidas Com A Assistência Ao Parto, Rev Latino-am Enfermagem. 13(6), 960-7.

Dodou, H. D. et al. (2014). Contribuição do acompanhante para humanização do parto: percepção das puérperas. Esc Anna Nery Rev Enferm. 18(2), 262-69.

Gois, F. L. M. et al. (2020). O uso da bola suíça no alivio da dor no trabalho de parto: revisão sistemática, Research, Society and Development. 9(7), e50973783.

Longo, C. M., Andraus, L. M. S., Barbosa, M. A. (2010). Participação do acompanhante na humanização do parto e sua relação com a equipe de saúde. Rev. Eletr. Enfermagem. 12 (2), 386-91.

Mandarino, N. R., et al. (2009). Aspectos relacionados à escolha do tipo de parto: um estudo comparativo entre uma maternidade pública e outra privada, em São Luís, Maranhão, Brasil. Cad. Saúde Pública. 25(7), 1587-1596.

Schillewaert, N., Langerak, F. \& Duhamel, T. (1998). Non-probability sampling for www surveys:a comparison of methods. Journal of Market Research Society. 40(4), 36-44.

Silva, R. M., et al. (2011). Planejamento familiar: significado para mulheres em idade reprodutiva. Ciênc. saúde coletiva 16(5), $2415-2424$.

Giacomini, S. M., \& Hirsch, (2020). Parto, O.N. “natural” elou "humanizado”? Uma reflexão a partir da classe, Rev. Estud. Fem. 28 (1).

Largura M. (2000). Assistência ao parto no Brasil: aspectos espirituais, psicológicos, biológicos e sociais. Uma análise crítica. Por um parto mais humano e solidário. (2a ed.), Sarvier.

Severo, R. D. et al. (2021). Vivências de puérperas em relação ao parto assistido por enfermeiras obstétricas. Research, Society and Development, 10(1), e42810111830

Souza, S. R. R. K. \& Gualda, D. M. R. (2016). A experiência da mulher e de seu acompanhante no parto em uma maternidade pública. Texto \& Contexto Enfermagem. 25(1), e4080014. 